\title{
Nitric oxide synthase inhibition impairs muscle regrowth following immobilization
}

\author{
Andreo Fernando Aguiar ${ }^{\mathrm{a}}{ }^{*}$, Ivan José Vechetti-Júnior ${ }^{\mathrm{b}}$, Rodrigo Wagner Souza ${ }^{\mathrm{b}}$, \\ Warlen Pereira Piedade ${ }^{b}$, Francis Lopes Pacagnelli ${ }^{c}$, André Soares Leopoldo ${ }^{\mathrm{d}}$, \\ Juliano Casonatto ${ }^{\mathrm{a}}$, Maeli Dal-Pai-Silva ${ }^{\mathrm{b}}$ \\ a Center of Research in Health Sciences, North University of Paraná (UNOPAR), Londrina, Paraná, Brazil \\ ${ }^{\mathrm{b}}$ Department of Morphology, São Paulo State University (UNESP), Botucatu, São Paulo, Brazil \\ c Department of Physiotherapy, University of Western São Paulo (UNOESTE), Presidente Prudente, São Paulo, Brazil \\ ${ }^{\mathrm{d}}$ Center of Physical Education and Sports, Department of Sports, Federal University of Espírito Santo, Vitória, Espírito Santo, Brazil
}

\section{A R T I C L E I N F O}

\section{Article history:}

Received 17 February 2017

Received in revised form

26 July 2017

Accepted 26 July 2017

Available online 28 July 2017

\section{Keywords:}

Plantaris

Cross-sectional area

Recovery

mTOR

Atrophy

Skeletal muscle

\begin{abstract}
A B S T R A C T
Nitric oxide (NO) has been shown to increase skeletal muscle protein synthesis. However, the role of NO during skeletal muscle regrowth after immobilization remains unknown. The purpose of this study was to determine whether NO is required for muscle regrowth/recovery after a period of disuse by immobilization. Male Wistar rats were divided into 4 groups: recovered, 1-(2-trifluoromethyl-phenyl)-imidazole (TRIM; $10 \mathrm{mg} \cdot \mathrm{kg}$ body mass ${ }^{-1} \cdot$ day $^{-1}$ ), $\mathrm{N}^{\mathrm{G}}$-nitro-L-arginine methyl ester (L-NAME; $90 \mathrm{mg} \cdot \mathrm{kg}$ body mass $^{-1} \cdot$ day $\left.^{-1}\right)$, and control. The recovered, TRIM, L-NAME groups were submitted to a $7-\mathrm{d}$ muscle recovery period (by remobilization), following a 10-d immobilization period (to induce plantaris [PLA] muscle atrophy). After the experimental period, the PLA muscle was collected for morphometrical (muscle fibers cross-sectional area [CSA]) and molecular (Phospho-mTOR ${ }^{\text {Ser2448 }}$ protein expression) analysis. After $7 \mathrm{~d}$ of recovery, the recovered group displayed complete muscle regrowth (CSA, recovered: $2.216 \pm 214$ vs. control: $\left.2.219 \pm 280 \mathrm{~cm}^{2} ; P>0.05\right)$. However, CSA of the L-NAME $\left(1.911 \pm 267 \mathrm{~cm}^{2}\right)$ and TRIM $\left(1.896 \pm 219 \mathrm{~cm}^{2}\right)$ groups were statistically $(P<0.05)$ lower than the recovered and control groups. Additionally, there was a $29 \%$ increase in Phos- $\mathrm{mTOR}^{\mathrm{Ser} 2448}$ protein expression levels in the recovered group compared to control group, and this increase was blocked in both TRIM and L-NAME groups. In conclusion, our results indicate that NO is crucial for skeletal muscle regrowth after an immobilization period, potentially via the mTOR signaling pathway.
\end{abstract}

๑๐ 2017 Elsevier Inc. All rights reserved.

\section{Introduction}

The primary objective of many studies associated with skeletal muscle wasting has been to understand the cellular and molecular mechanisms that govern skeletal muscle mass during and in recovery from immobilization. The debilitating effects of immobilization on muscle tissue include a reduction in cross-sectional area (CSA), reduction of strength, increased protein degradation/synthesis ratio, and a reduction oxygen supply (for review see Ref. [4]). It has been suggested that these negative effects may be attenuated

\footnotetext{
* Corresponding author. Center of Research in Health Sciences, North University of Paraná (UNOPAR), Avenue Paris, 675, Jardim Piza, CEP: 86041-120, Londrina, PR, Brazil.

E-mail address: afaguiarunesp@gmail.com (A.F. Aguiar).
}

by activation of multiple anabolic signaling pathways, including the insulin-like growth factor 1 (IGF-I) pathway [7,35].

IGF-I has been characterized as a crucial regulator of skeletal muscle growth by 1) stimulating satellite cells to proliferate and differentiate during the compensatory hypertrophy process [1], and/or 2) by activating a cascade of signaling pathways via phosphatidylinositol 3-kinase (PI3K)/Akt/mTOR/p70S6 kinase (p70S6K), resulting in the downstream activation of targets required for protein synthesis $[18,26]$. The importance of IGF-I pathway in regulating muscle growth was demonstrated by in vivo and in vitro studies that used pharmacological treatment with rapamycin to selectively inhibit the function of mTOR. For instance, the inhibition of mTOR with rapamycin has been shown to reduce the activation of p70S6K and completely block the compensatory PLA muscle hypertrophy during synergist ablation [7]. In addition, treatment 
with rapamycin inhibited the fiber growth and phosphorylation of p70S6K in regenerating muscles [24]. The role of IGF-I/mTOR/ p70S6K pathway during muscle growth has also been investigated in mice. Transgenic mice that overexpress IGF-I in skeletal muscle exhibit greater hypertrophy [10], indicating that IGF-I/ mTOR/p70S6K pathway is a crucial regulator of muscle growth.

Although there is strong evidence to show that IGF-I/mTOR pathway is a crucial regulator of muscle mass, it has recently been suggested that nitric oxide (NO) may also be a common regulator of this process. NO is a very small, freely diffusible molecule produced at high levels in skeletal muscle [30] by neuronal nitric oxide synthase (nNOS) that catalyzes the conversion of L-arginine to L-citrulline and generates the NO [9]. In addition to nNOS, endothelial NOS (eNOS) is also expressed in skeletal muscle [19,30], and the importance of these enzymes on muscle tissue has been evidenced using pharmacological inhibitors (e.g., TRIM and L-NAME) $[3,22,28]$ and NOS knockout mice [3]. For example [3], showed that pharmacological inhibition of NOS activity delayed the hypertrophy in mice skeletal muscle after injury, suggesting that NO production may be crucial to muscle regeneration. In line with this observation, it has been shown that NOS activity in skeletal muscle is associated with regulation of contractile protein gene expression [28], mTOR phosphorylation [16], muscle fiber density [21], force development [8], as well as role in muscle regeneration [14]. It is therefore possible that NOS-derived NO interacts with the IGF-I/mTOR pathway in control of skeletal muscle mass. However, to date no study has examined the role of NOS-derived NO and their possible interactions with mTOR pathway during muscle regrowth process after immobilizationinduced atrophy in normal rats.

The purpose of this study was to determine whether NOSderived NO plays a role in muscle regrowth after a period of immobilization in predominantly fast-twitch muscles. In addition, we analyzed whether stimulation of the mTOR pathway is dependent on NOS-derived NO presence. We tested the hypothesis that NO inhibition via TRIM and L-NAME during recovery period would attenuate muscle regrowth by attenuate the stimulation of the mTOR pathway.

\section{Methods}

\subsection{Animals}

Thirty-nine male Wistar rats (350-400 g) were obtained from Central Biotery of Londrina State University (UEL). They were housed in collective polypropylene cages (4 animals per cage) covered with metallic grids, in a temperature-controlled room $\left(22-24{ }^{\circ} \mathrm{C}\right.$ with relative humidity of $55-66 \%$ ), on a 12 :12-h light-dark cycle. All animals were provided with unlimited access to standard rat chow and water. All experimental procedures involved in this study were approved by the Ethics Committee for Animal Experiments of the North University of Paraná, Londrina, PR, Brazil (Protocol No. 018/11). Animals received care in compliance with the "Principles of Laboratory Animal Care" formulated by the National Society for Medical Research and the "Guide for the Care and Use of Laboratory Animals" prepared by the Institute of Laboratory Animal Research and published by the National Institutes of Health (NIH Publications No. 8023, revised 1978).

\subsection{Experimental protocol}

Initially, the animals were divided into 2 groups: immobilized $(N=31)$ and age-matched control $(N=8)$ (Fig. 1$)$. The immobilized group was submitted to a 10 -d cast immobilization period to induce PLA muscle atrophy, while the age-matched control group remained in their cage and was free to move (uncasted). Subsequently, 7 animals from the immobilized group and all control animals $(N=8)$ were euthanized for validation of PLA atrophy. Validation was done by directly comparing muscle fiber CSA in each group. Finally, the remaining immobilized animals $(N=24)$ were randomly divided into 3 groups: recovered $(N=6)$, TRIM $(N=7)$, and L-NAME $(N=7)$. The recovered, TRIM, and L-NAME groups were remobilized during a 7-d muscle recovery period, to examine the possible effects of systemic inhibition of the NOS (nNOS and eNOS) on muscle regrowth (Fig. 1). During the 7-d recovery period, the animals remained in their cages and allowed to move freely. Some rats (recovered: 2, TRIM: 1, and L-NAME: 1 ) were excluded during the study due to behavior problems (i.e., aggression). One day after the recovery period, the animals were anesthetized with pentobarbital sodium $\left(40 \mathrm{mg}^{-1} \cdot \mathrm{kg}\right.$, i.p) and euthanized by decapitation. The PLA muscle of each leg was removed, frozen in liquid nitrogencooled isopentane, and then stored at $-80{ }^{\circ} \mathrm{C}$ until analysis. The right and left muscles were collected for muscle fiber CSA and Phospho-mTOR ${ }^{\text {Ser2448 }}$ protein expression analyses, respectively. The right muscle weight was used as an indirect indicator of atrophy to corroborate the CSA data. We analyzed the PLA muscle because NOS is highly expressed in predominantly fast-twitch muscle (e.g., EDL, gastrocnemius, PLA) rather than slow-twitch muscles (e.g., soleus) [13,19,21]. Moreover, slow fibers showed only weak NOS immunoreactivity [25] and nNOS was more concentrated in the fast-twitch (type II) fibers than in the slowtwitch (type I) fibers [30].

\subsection{Cast immobilization}

The cast immobilization of both hindlimbs was performed according to an adapted version as described by Ref. [15]. Briefly, animals were anesthetized with a mixture of ketamine $\left(50 \mathrm{mg}^{-1} \cdot \mathrm{kg}\right.$, i.p) and xylazine $\left(10 \mathrm{mg}^{-1} \cdot \mathrm{kg}\right.$, i.p) to ensure complete sedation during the procedure. Hindlimbs were immobilized with a fast-drying plaster bandage from the hip to the ankle, to keep the PLA muscle in a neutral position during the $10 \mathrm{~d}$ of immobilization [11]. Animals were free to move using their forelimbs and ate and drank ad libitum. Drinking water was replaced, and body weight as well as food intake were recorded every two days throughout the experimental period. Rats were monitored daily for chewed plaster, attritions, venous occlusion, and problems with ambulation.

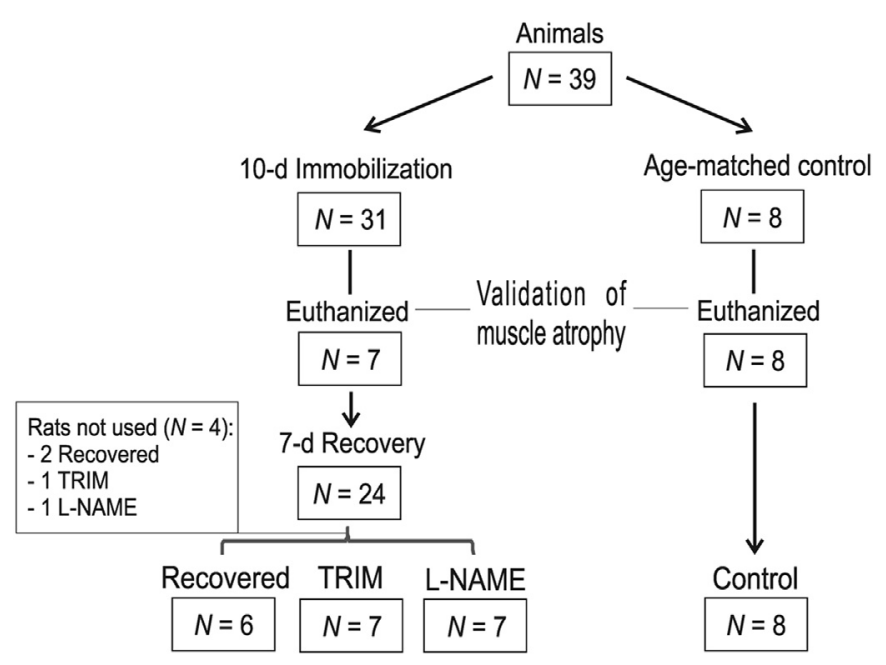

Fig. 1. Experimental design. 


\subsection{Inhibition of NOS activity}

The pharmacological inhibition of NOS was performed by administering the non-isoform-specific NOS inhibitor L-NAME (Sigma-Aldrich ${ }^{\circledR}$ ) or the selective nNOS inhibitor TRIM (Cayman Chemical ${ }^{\circledR}$ ) during the 7-d recovery period. L-NAME was dissolved in phosphate-buffered saline (PBS) and administrated via oral gavage, once daily, at a dose of $90 \mathrm{mg} \cdot \mathrm{kg}$ body mass ${ }^{-1} \cdot$ day $^{-1}$. TRIM was dissolved in PBS and injected i.p, once daily, at a dose of $10 \mathrm{mg} \cdot \mathrm{kg}$ body mass $^{-1} \cdot \mathrm{day}^{-1}$ [28]. L-NAME and TRIM were chosen because they have been validated in several studies $[6,28,29,31]$, and such doses have been shown to effectively inhibit systemic NO production (i.e., lower nitrate plus nitrite levels) [28], NO synthesis [31] and skeletal muscle NOS activity [6,29], without apparent adverse effects. To control for possible stressor effects of the injection and gavage needles, the other groups were also injected and received gavage, with an equivalent vehicle amount.

\subsection{Serum nitrate/nitrite}

Systemic NOS inhibition was confirmed by measurement of serum nitrate plus nitrite levels from each animal. Blood samples were collected immediately after euthanation and then centrifuged at $2000 \mathrm{~g}$ for $15 \mathrm{~min}$. Serum was collected and stored at $-80^{\circ} \mathrm{C}$ until analysis. Samples were thawed, diluted 1:1 with PBS, and filtered with Millipore UltrafreeMC microcentrifuge filter cups $(10,000$ molecular weight cutoff). Aliquots from each sample were analyzed in duplicate by using a fluorometric assay kit for nitrate plus nitrite (Cayman Chemical ${ }^{\circledR}$; Ann Arbor, Michigan, USA).

\subsection{Cross-sectional area}

PLA histological sections (10 $\mu \mathrm{m}$ thick) were obtained using a cryostat (JUNG CM1800, Leica, Germany) at $-24{ }^{\circ} \mathrm{C}$ and stained with hematoxylin and eosin (HE). The stained sections were used for photographic documentation of 3 random histological fields $(20 \times$ lens $)$ of each animal, corresponding to $~ 500$ muscle fibers. The same blinded investigator was responsible for selecting histological fields of each animal. Muscle fiber CSA was manually outlined and calculated by the software (Leika QWin Plus, Germany).

\subsection{Western blot}

Protein levels of Phospho-mTOR ${ }^{\mathrm{Ser} 2448}$ and GAPDH were quantified by Western blot assays in PLA muscle extracts. Muscle samples were homogenized in lysis buffer (1\% Triton X-100, $10 \mathrm{mM}$ sodium pyrophosphate, $100 \mathrm{mM} \mathrm{NaF}, 10 \mathrm{mg} / \mathrm{mL}$ aprotinin, $1 \mathrm{mM}$

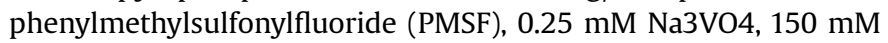
$\mathrm{NaCl}$ and $50 \mathrm{mM}$ Tris- $\mathrm{HCl} \mathrm{pH}$ 7.5). Protein homogenates were mixed with 2X Laemmli's buffer and boiled. Denatured proteins were separated by SDS-PAGE and transferred to a nitrocellulose membrane (Bio-Rad Laboratories, Hercules, CA, USA). Membranes were blocked for $1 \mathrm{~h}$ in $5 \%$ milk in TBST solution at room temperature and probed using specifics antibodies for Phospho-mTOR ${ }^{\text {Ser2448 }}$ (1:1000) and GAPDH (1:1000) (Cell Signaling Technology; Beverly, MA). Primary antibodies were incubated overnight at $40 \mathrm{C}$ in blocking buffer followed by the appropriate secondary antibodies, 1:5000 dilution (Cell Signaling Technology; Beverly, MA), conjugated with horseradish peroxidase for $1 \mathrm{~h}$ at room temperature. Finally, the proteins were detected using SuperSignal West Pico Chemiluminescent Substrate Kit (Thermo Fisher Scientific, Rockford, IL, USA), according to the manufacturer's instructions. The chemiluminescent signal was visualized and quantified by densitometry using the image analyzer ImageQuant 350 (GE Healthcare,
Little Chalfont, UK). The values were normalized by the values obtained for GAPDH protein.

\subsection{Statistical analysis}

Data are expressed as means \pm SD. Muscle weight, body weight, food intake, and CSA data were compared among groups using oneway ANOVA tests. When significant differences were detected with ANOVA, multiple comparison testing was performed using Bonferroni post hoc two-tailed analysis. The significance level was set at $P \leq 0.05$. Statistical analyses were performed using SPSS statistical analysis software (SPSS version 20.0; Chicago, IL, USA). Phospho-mTOR protein expression data were compared among the recovered groups (recovered, L-NAME, and TRIM) and control using the effect size (ES) and confidence interval (CI).

\section{Results}

\subsection{Body (BW) and muscle (MW) weights}

The BW and MW for each group are shown in Fig. 2. After $7 \mathrm{~d}$ of recovery, the BW and MW were significantly $(P<0.05)$ lower in the L-NAME (control-relative \% difference, BW: $-21 \%$ and MW: $-25 \%$ ) and TRIM (control-relative \% difference, BW: $-22 \%$ and MW: $-30 \%$ ) groups, compared with the recovered and control groups. No significant $(P>0.05)$ difference was observed between the L-NAME and TRIM groups.

\subsection{Food intake}

There was no significant difference in daily food intake among the groups (control: $147.4 \pm 12.6$ g; recovered: $155.4 \pm 15.7 \mathrm{~g}$; $\mathrm{L}-$
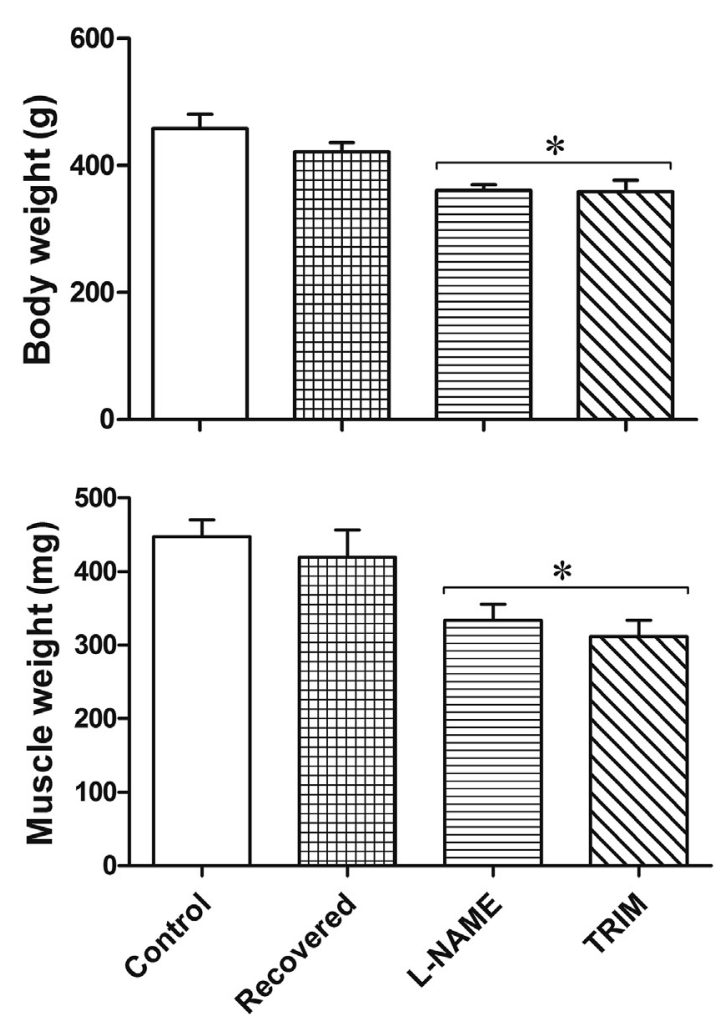

Fig. 2. Body (upper) and right muscle (lower) weight in the control $(N=8)$, recovered $(N=6)$, L-NAME $(N=7)$, and TRIM $(N=7)$ groups. Values are mean \pm SD. ${ }^{*} P<0.05$ compared to control and recovered groups. 
NAME: $151.3 \pm 16.0 \mathrm{~g}$, and TRIM: $149.3 \pm 13.9 \mathrm{~g} ; P>0.05)$. These results indicated that the loss of body weight in the NAME and TRIM groups were caused by physiological (e.g., muscle atrophy), but not behavioral changes (e.g., decrease in food intake).

\subsection{Cross-sectional area (CSA)}

The CSA data for each group is shown in Fig. 3. After a 10d immobilization period, there was a significant $(P<0.05) 22 \%$ reduction in muscle fibers CSA in the immobilized group compared to control, confirming the efficacy of the immobilization protocol to induce muscle atrophy. After $7 \mathrm{~d}$ of recovery, there was no significant $(P>0.05)$ difference in CSA between the recovered and control groups, indicating that the 7-d period was sufficient to promote total muscle recovery. In addition, there were significant $(P<0.05)$ decreases in CSA of the immobilized, L-NAME, and TRIM groups compared to control and recovered groups. However, no significant difference $(P>0.05)$ was observed in CSA among the immobilized, L-NAME, and TRIM groups, suggesting that systemic inhibition of NOS impaired muscle regrowth.

\subsection{Protein expression}

The protein expression data for each group is shown in Fig. 4. After $7 \mathrm{~d}$ of recovery, there was a $29 \%$ increase in Phospho$\mathrm{mTOR}^{\mathrm{Ser} 2448}$ protein expression levels in the recovered group compared to control group, and this increase was blocked with the inhibition of NOS activity in both TRIM and L-NAME groups.

\subsection{Serum nitrate/nitrite}

There was a significant $(P<0.05)$ reduction in serum nitrate plus nitrite levels in the L-NAME $(3.28 \pm 1.34 \mu \mathrm{M})$ and TRIM $(5.82 \pm 1.57 \mu \mathrm{M})$ groups, compared to control group

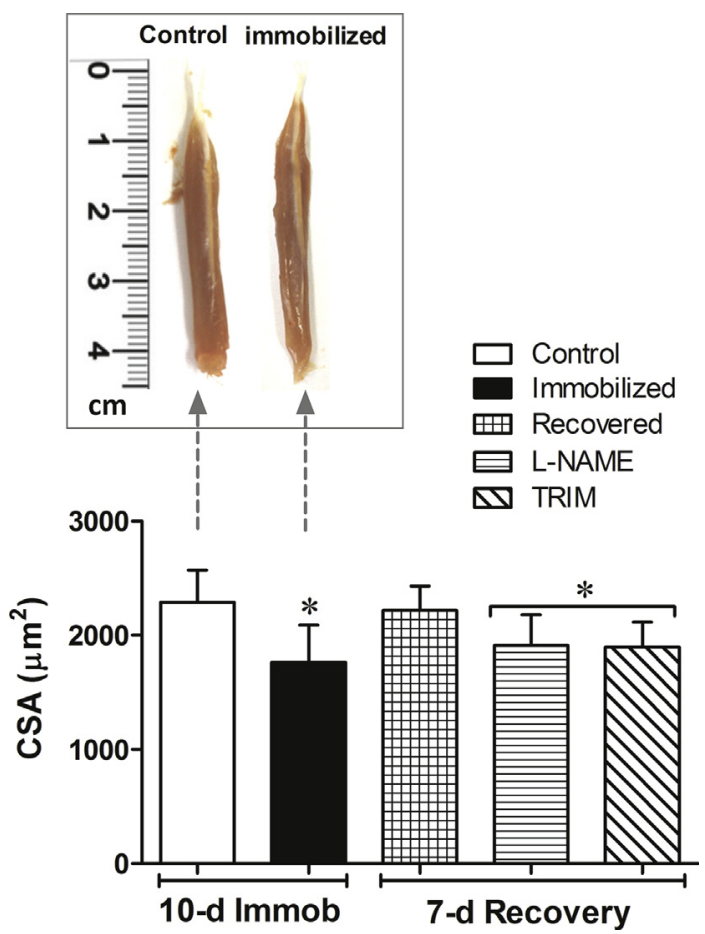

Fig. 3. Cross-sectional area (CSA) of plantaris muscle in the control $(N=8)$, recovered $(N=6)$, L-NAME $(N=7)$, and TRIM $(N=7)$ groups. Values are mean \pm SD. ${ }^{*} P<0.05$ compared to control and recovered groups.

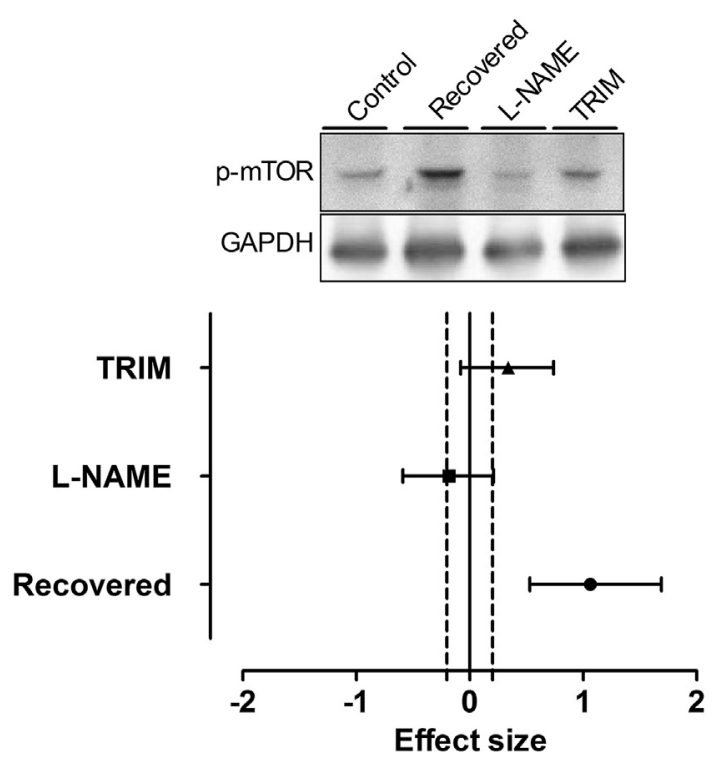

Fig. 4. Effect size and confidential interval for the difference in Phospho-mTOR protein expression between control $(N=8)$, recovered $(N=6)$, L-NAME $(N=7)$, and TRIM $(N=7)$ groups. Note: The point " 0 " indicates the control group. There was an increase in Phospho-mTOR expression in recovered group compared to control.

$(9.43 \pm 1.61 \mu \mathrm{M})$. This result indicates that the drugs successfully inhibited systemic NOS activity.

\section{Discussion}

To our knowledge this is the first study to examine the effects of NOS inhibition during muscle regrowth following immobilizationinduced atrophy in rat skeletal muscle. We hypothesized that NOS inhibition during recovery period would affect muscle regrowth by influencing the stimulation of the mTOR signaling pathway. The major findings of this study were that NOS inhibition: 1) impaired skeletal muscle regrowth (during remobilization) following immobilization, and 2) blocked the increase in Phos-mTOR expression.

The 10-d immobilization protocol used in the present study was effective at inducing atrophy in the PLA muscle. A direct statistical comparison showed that immobilized group exhibited a $22 \%$ reduction in the muscle fiber CSA compared to control group (Fig. 3). These results were corroborated by body (immobilized: $354 \pm 32$ vs. control: $458 \pm 63 \mathrm{~g} ; P<0.05$ ) and muscle (immobilized: $339.2 \pm 57 v s$. control: $448 \pm 64 \mathrm{mg} ; P<0.05)$ weight differences (Fig. 2). Moreover, no significant difference was found in daily food intake among the experimental groups, indicating that the loss of body weight in the immobilized group was caused by physiological (e.g., muscle atrophy), but not behavioral changes (e.g., decrease in food intake). The muscle loss identified in our study is perhaps not surprising considering previous studies that showed reduction of sarcomere diameter in the PLA muscle [17] and soleus muscle weight [11] following 10 and $7 \mathrm{~d}$ of unloading (tail-suspended) and immobilization (with acrylic resin orthosis), respectively. Therefore, it appears that a period between 7 and $10 \mathrm{~d}$ of muscle inactivity is sufficient to induce a marked reduction in muscle mass.

A novel and important finding from this study was that after $7 \mathrm{~d}$ of recovery, the recovered group displayed a complete muscle regrowth in relation to control group, but the TRIM and L-NAME groups remained atrophied (Fig. 3). This negative effect of NOS inhibition on muscle regrowth supports the thesis that NO may be a 
positive modulator of protein synthesis and consequently skeletal muscle growth. In line with this hypothesis [22], showed that inhibition of the NOS isoforms eNOS and nNOS with L-NAME and TRIM reduced sarcomere addition and muscle weight during muscle regrowth (by remobilization) after a 3-wk immobilization period. The authors also showed that supplementation with Larginine, a substrate for NOS and the main precursor of NO, enhanced sarcomere addition during muscle regrowth, suggesting that an increase in NOS-mediated NO production may be important for this process. Additionally, it has been shown that NO partly alleviates muscle dystrophy and improves muscle repair in mdx mice $[2,5,27,32]$, while the NOS inhibition can delay and restrict the extent of repair in cells isolated from muscle after injury [3]. These negative effects of NOS inhibition were associated with an impairment in upregulation of contractile protein synthesis (e.g., alpha actin, and type I myosin heavy chain [MHC] mRNA) during compensatory overload (by synergist ablation) in rat skeletal muscle [28]. Therefore, it seems that NOS-derived NO may play an important role in protein synthesis and consequently muscle regrowth during recovery process in normal rats. Our results are consistent with this assertion.

The exact mechanism(s) underlying the role of NO on skeletal muscle recovery remain to be determined, but could potentially involve the stimulation of mTOR pathway. In the current study, the complete recovery of mass muscle observed in recovered group (Fig. 3) was associated with an upregulation in mTOR protein expression, compared to control group (Fig. 4). This result is perhaps not surprising considering the important and welldocumented role of the mTOR pathway during muscle hypertrophy [7] and regeneration [36] process. However, a novel and important finding from this study was that the NOS inhibition impaired muscle regrowth and blocked the upregulation in mTOR protein expression after $7 \mathrm{~d}$ of recovery. In line with our observations [12], showed that nNOS absence in NOS1-/- mice affected myofibre growth and inhibited the mTOR signaling pathway, suggesting a possible interaction between NO production and mTOR activity in control of muscle mass. This premise was supported by a previous animal study that stimulated NO production in skeletal muscle [34]. The authors showed that increased NO production with L-arginine supplementation enhanced muscle protein synthesis and activation of mTOR signaling pathways in skeletal muscle of neonatal pigs. Our findings, in conjunct with these abovementioned studies [12,34], indicate that NO derived from NOS may be a positive regulator of the mTOR pathway, and that this combined action is crucial for muscle regrowth/growth. Considering this evidence, it seems likely that pharmacological therapies to increase NOS synthesis and/or its substrates (e.g., L-arginine) may prevent loss of muscle or ameliorate muscle regrowth in several conditions associated with disuse and immobilization. However, further research is required to clarify the relationship between NO and mTOR pathway in human muscle before such conclusions can be reached.

Although the present investigation provides novel information for the literature, a few limitations must be acknowledged. Firstly, we examined only the plantar muscle, which is composed predominantly of type II fibers, thus we cannot exclude the possibility that inhibition of NOS could have another effect on predominantly oxidative muscles (e.g. soleus). Secondly, we did not analyze other possible NO actions on skeletal muscle, for instance, endothelial vasodilation and activation of satellite cell (CS). NO release from endothelial cells has been shown to promote vasodilation [23], and activate the CS [33] in skeletal muscle. Given that vasodilation (i.e., increased blood flow) and CS activation are required to muscle function, growth and regeneration $[3,12,14,20]$ we cannot exclude the possibility that NO inhibition impaired these factors, and consequently muscle regrowth during remobilization. Further studies are required to address these issues.

\section{Conclusion}

Our results indicate that NO is crucial for skeletal muscle regrowth after a period of immobilization in rodents, potentially via the mTOR signaling pathway. These results have significant clinical implications for the design of effective therapeutic strategies to improve regeneration/regrowth of skeletal muscle after disuse conditions. However, further studies, particularly in humans, are required to better understanding of the relationship between $\mathrm{NO}$ and other anabolic pathways (e.g., CS) in different muscles (i.e., oxidative and glycolytic), and how NO interacts with nutrients and exercise stimulus to expedite muscle repair.

\section{Acknowledgements}

We thank Dr. Chris McGlory for his precious help in reviewing the manuscript.

\section{Funding}

This work was supported by the North University of Paraná (UNOPAR) (Grant number: PP/0020/12).

\section{References}

[1] G.R. Adams, S.A. McCue, Localized infusion of IGF-I results in skeletal muscle hypertrophy in rats, J. Appl. Physiol. 84 (1998) 1716-1722.

[2] J.E. Anderson, C. Vargas, Correlated NOS-Imu and myf5 expression by satellite cells in mdx mouse muscle regeneration during NOS manipulation and deflazacort treatment, Neuromuscul. Disord. 13 (2003) 388-396.

[3] J.E. Anderson, A role for nitric oxide in muscle repair: nitric oxide-mediated activation of muscle satellite cells, Mol. Biol. Cell 11 (2000) 1859-1874.

[4] H.J. Appell, Muscular atrophy following immobilisation. A review, Sports Med. 10 (1990) 42-58.

[5] J.D. Archer, C.C. Vargas, J.E. Anderson, Persistent and improved functional gain in mdx dystrophic mice after treatment with L-arginine and deflazacort, FASEB J. 20 (2006) 738-740.

[6] T.W. Balon, A.P. Jasman, J.C. Young, Effects of chronic N(omega)-nitro-Larginine methyl ester administration on glucose tolerance and skeletal muscle glucose transport in the rat, Nitric Oxide 3 (1999) 312-320.

[7] S.C. Bodine, T.N. Stitt, M. Gonzalez, W.O. Kline, G.L. Stover, R. Bauerlein, E. Zlotchenko, A. Scrimgeour, J.C. Lawrence, D.J. Glass, Yancopoulos GD Akt/ mTOR pathway is a crucial regulator of skeletal muscle hypertrophy and can prevent muscle atrophy in vivo, Nat. Cell Biol. 3 (2001) 1014-1019.

[8] J.E. Brenman, D.S. Chao, H. Xia, K. Aldape, D.S. Bredt, Nitric oxide synthase complexed with dystrophin and absent from skeletal muscle sarcolemma in Duchenne muscular dystrophy, Cell 82 (1995) 743-752.

[9] K. Ckless, A. van der Vliet, Y. Janssen-Heininger, Oxidative-nitrosative stress and post-translational protein modifications: implications to lung structurefunction relations. Arginase modulates NF-kappaB activity via a nitric oxidedependent mechanism, Am. J. Respir. Cell Mol. Biol. 36 (2007) 645-653.

[10] M.E. Coleman, F. DeMayo, K.C. Yin, H.M. Lee, R. Geske, C. Montgomery R.J. Schwartz, Myogenic vector expression of insulin-like growth factor-1 stimulates muscle cell differentiation and myofiber hypertrophy in transgenic mice, J. Biol. Chem. 270 (1995) 12109-12116.

[11] C.A. da Silva, R.R. Guirro, M.L. Polacow, K.M. Cancelliero, J.L. Durigan, Rat hindlimb joint immobilization with acrylic resin orthoses, Braz J. Med. Biol. Res. 39 (2006) 979-985.

[12] C. de Palma, F. Morisi, S. Pambianco, E. Assi, T. Touvier, S. Russo, C. Perrotta, V. Romanello, S. Carnio, V. Cappello, P. Pellegrino, C. Moscheni, M.T. Bassi, M. Sandri, D. Cervia, E. Clementi, Deficient nitric oxide signaling impairs skeletal muscle growth and performance: involvement of mitochondrial dysregulation, Skelet. Muscle 4 (2014) 22.

[13] Q. El-Dwairi, Y. Guo, A. Comtois, E. Zhu, M.T. Greenwood, D.S. Bredt S.N. Hussain, Ontogenesis of nitric oxide synthases in the ventilatory muscles, Am. J. Respir. Cell Mol. Biol. 18 (1998) 844-852.

[14] L.I. Filippin, A.J. Moreira, N.P. Marroni, R.M. Xavier, Nitric oxide and repair of skeletal muscle injury, Nitric Oxide 21 (2009) 157-163.

[15] T.N. Frimel, F. Kapadia, G.S. Gaidosh, Y. Li, G.A. Walter, K. Vandenborne, A model of muscle atrophy using cast immobilization in mice, Muscle Nerve 32 (2005) 672-674.

[16] R.A. Frost, G.J. Nystrom, C.H. Lang, Endotoxin and interferon-gamma inhibit translation in skeletal muscle cells by stimulating nitric oxide synthase 
activity, Shock 32 (2009) 416-426.

[17] F.M. Giordano, E. Vizziello, J.G. Tidball, Falcieri, E.D. Curzi, Plantaris muscle adaptation to atrophy generated by disuse: an ultrastructural study, Microscopie 11 (2014) 31-36.

[18] D.L. Glass, Molecular mechanisms modulating muscle mass, Trend Mol. Med 9 (2003) 344-350.

[19] S. Kapur, S. Bédard, B. Marcotte, C.H. Côté, A. Marette, Expression of nitric oxide synthase in skeletal muscle: a novel role for nitric oxide as a modulator of insulin action, Diabetes 46 (1997) 1691-1700.

[20] Y.M. Kobayashi, E.P. Rader, R.W. Crawford, N.K. Iyengar, D.R. Thedens, J.A. Faulkner, S.V. Parikh, R.M. Weiss, J.S. Chamberlain, S.A. Moore K.P. Campbell, Sarcolemma localized nNOS is required to maintain activity after mild exercise, Nature 456 (2008) 511-515.

[21] L. Kobzik, M.B. Reid, D.S. Bredt, J.S. Stamler, Nitric oxide in skeletal muscle Nature 372 (1994) 546-548.

[22] T.J. Koh, J.G. Tidball, Nitric oxide synthase inhibitors reduce sarcomere addition in rat skeletal muscle, J. Physiol. 519 (1999) 189-196.

[23] A.J. Maxwell, E. Schauble, D. Bernstein, J.P. Cooke, Limb blood flow during exercise is dependent on nitric oxide, Circulation 98 (1998) 369-374.

[24] G. Pallafacchina, E. Calabria, A.L. Serrano, J.M. Kalhovde, S. Schiaffino, A protein kinase B-dependent and rapamycin- sensitive pathway controls skeletal muscle growth but not fiber type specification, Proc. Natl. Acad. Sci. U. S. A. 99 (2002) 9213-9218.

[25] K. Punkt, M. Fritzsche, C. Stockmar, P. Hepp, C. Josten, M. Wellner, S. Schering I.B. Buchwalow, Nitric oxide synthase in human skeletal muscles related to defined fibre types, Histochem Cell Biol. 125 (2006) 567-573.

[26] C. Rommel, S.C. Bodine, B.A. Clarke, R. Rossman, L. Nunez, T.N. Stitt, G.D. Yancopoulos, D.J. Glass, Mediation of IGF-1-induced skeletal myotube hypertrophy by $\mathrm{PI}(3) \mathrm{K} / \mathrm{Akt} / \mathrm{mTOR}$ and $\mathrm{PI}(3) \mathrm{K} / \mathrm{Akt} / \mathrm{GSK}$ pathways, Nat. Cell Biol. 3 (2001) 1009-1013.
[27] L. Segalat, K. Grisoni, J. Archer, C. Vargas, A. Bertrand, J.E. Anderson, CAPON expression in skeletal muscle is regulated by position, repair, NOS activity, and dystrophy, Exp. Cell Res. 302 (2005) 170-179.

[28] J.E. Sellman, K.C. DeRuisseau, J.L. Betters, V.A. Lira, Q.A. Soltow, J.T. Selsby, D.S. Criswell, In vivo inhibition of nitric oxide synthase impairs upregulation of contractile protein mRNA in overloaded plantaris muscle, J. Appl. Physiol. 100 (2006) 258-265, 1985.

[29] L.W. Smith, J.D. Smith, D.S. Criswell, Involvement of nitric oxide synthase in skeletal muscle adaptation to chronic overload, J. Appl. Physiol. 92 (2002) 2005-2011.

[30] J.S. Stamler, G. Meissner, Physiology of nitric oxide in skeletal muscle, Physiol. Rev. 81 (2001) 209-237.

[31] P. Sventek, A. Turgeon, E.L. Schiffrin, Vascular endothelin-1 gene expression and effect on blood pressure of chronic ETA endothelin receptor antagonism after nitric oxide synthase inhibition with L-NAME in normal rats, Circulation 95 (1997) 240-244.

[32] M. Wehling, M.J. Spencer, J.G. Tidball, A nitric oxide synthase transgene ameliorates muscular dystrophy in mdx mice, J. Cell Biol. 155 (2001) $123-131$.

[33] A.C. Wozniak, J.E. Anderson, Nitric oxide-dependence of satellite stem cell activation and quiescence on normal skeletal muscle fibers, Dev. Dyn. 236 (2007) 240-250.

[34] K. Yao, Y.L. Yin, W. Chu, Z. Liu, D. Deng, T. Li, R. Huang, J. Zhang, B. Tan, W. Wang, G. Wu, Dietary arginine supplementation increases mTOR signaling activity in skeletal muscle of neonatal pigs, J. Nutr. 138 (2008) 867-872.

[35] P. Zhang, X. Chen, M. Fan, Signaling mechanisms involved in disuse muscle atrophy, Med. Hypotheses 69 (2007) 310-321.

[36] P. Zhang, X. Liang, T. Shan, Q. Jiang, C. Deng, R. Zheng, S. Kuang, mTOR is necessary for proper satellite cell activity and skeletal muscle regeneration, Biochem. Biophys. Res. Commun. 463 (2015) 102-108. 